\title{
Lectura de los espacios de la memoria: El museo en la narrativa de José María Merino
}

Reading of memory spaces: The museum in the narrative of José María Merino

ANNA GABRIELA DIAKOW

Northwestern University

Estados Unidos

Resumen. El presente artículo intenta mostrar la representación del museo en la narrativa de José María Merino y el diálogo que establece con las principales "teorías del museo". El resultado del dicho diálogo es una reflexión sobre la imposibilidad de la recreación del pasado en el espacio museístico. Mediante el análisis de tres representaciones del museo provenientes de la narrativa del autor escrita en los años 80, dos novelas y un cuento, se presenta una lectura singular y problemática de este espacio, y en consecuencia, su participación en el discurso de desconocimiento y desorientación del personaje deseoso de reconstruir su pasado y con ello su identidad. Se postula así la necesidad de la memoria viva del individuo visitante que inicia una interacción con los objetos del museo.

Palabras clave: museo; memoria; identidad; Merino; narrativa.

\begin{abstract}
This article attempts to show the museum's representation in the narrative of José María Merino and dialogue established with the main "theories of the museum." The result of this dialogue is a reflection on the impossibility of recreating the past in the museum space. By analyzing three representations of the museum in the narrative of the author written in the 1980's, this article presents a unique and challenging reading of this space and its participation in the discourse of ignorance and confusion of the character willing to reconstruct his past and identity. It proposes the need for the living memory of the individual visitor that begins to interact with museum objects.
\end{abstract}

Keywords: museum; memory; identity; Merino; narrative. 
Somos nuestra memoria, somos ese quimérico museo de formas inconstantes ese montón de espejos rotos.

\section{(J. L. Borges)}

La marcada presencia del espacio es una constante que se mantiene viva en la narrativa de José María Merino en los ochenta. La preocupación espacial del autor se da ante todo en la empresa reivindicadora del territorio geográfico de León y su provincia, lugar de la infancia y parte de la juventud de Merino. Los paisajes y entornos concretos del noroeste aparecen detalladamente descritos no como mero trasfondo de acciones sino como agentes de principales funciones narrativas. Con frecuencia también los espacios leoneses vienen dotados de fuerzas singulares generadoras de un relato fantástico o un paisaje insólito y fantasmagórico que le recuerda al lector los espacios de la Región benetiana. De ejemplo nos pueden servir algunos relatos recogidos en la colección Cuentos del reino secreto (1982). Sin embargo, vale decir que el interés del autor por lo espacial no se limita exclusivamente a los escenarios geográficos de su experiencia personal. También es frecuente en la obra de Merino la reiteración de espacios sin identificación geográfica, menos concretos y tangibles que sirven como motores de narración, se les encomiendan funciones reservadas a los personajes o actúan a modo de intermediarios entre personajes y su experiencia pasada. Uno de estos espacios de marcada y mantenida presencia llega a ser el museo vinculado a cuestiones de la memoria, la recuperación del pasado y la identidad.

Museo del Río o la muerte del pasado

La primera representación meriniana del museo viene de la novela El caldero de oro (1981), cuyo protagonista regresa al pueblo natal en el noroeste, decepcionado por su enajenada existencia en la ciudad, esperando así recuperar el paraíso perdido de la infancia. El nuevo museo que acaba de estrenarse en el pueblo, el Museo del Río, establecido en el edificio del antiguo monasterio, aparece descrito por el protagonista de la manera siguiente: 
Más allá, el monasterio, con las luces de ese cartel que le anuncia como museo todas las noches de todos los días, laborales y feriados, las letras enormes que desde esa posición en que estabas no podían leerse, [...] esas letras que anuncian el Museo del Río, ahora que las viejas piedras ya no albergan a los monjes, sino a toda la teoría arqueológica que sirve de mayor esplendor para la publicidad del complejo: las hachas, las lanzas, las fíbulas, los exvotos antropomorfos, las vasijas, las agujas, alternando su impávida presencia con las reproducciones de los viejos hórreos, de los carros, de los trillos y de los forcados, las fotos de boleras y pallozas, las estelas y las aras con las invocaciones a los dioses y a las diosas que murieron ya para siempre. (Merino, 1981: 26-7)

El personaje recrea en su memoria la imagen del museo -una institución con fines comerciales -que llega a ser uno de los signos que anuncian la llegada del progreso al pueblo. El museo ocupa el antiguo monasterio reemplazando así la auténtica vida de sus habitantes llena de costumbres y ritos religiosos, que solían marcar la existencia de los monjes, con la teoría arqueológica muerta cuyo único objetivo anunciado por medio del cartel parece ser el fomento de la publicidad para atraer más turistas. El antiguo espacio viene invadido por una acumulación de objetos -en su mayoría de uso cotidiano- que ya han dejado de cumplir una función utilitaria en su medio natural y mezclados ahora con reproducciones y fotografías de distintas épocas sirven para conservar y constituir una representación científica y artificial del pasado unívoco y estático.

La memoria viva parece no tener acceso a este espacio donde queda sustituida por una memoria muerta almacenada en reproducciones y objetos descontextualizados que "murieron para siempre" (Merino, 1981: 27). A. Green (1998) en su ensayo dedicado a la transformación por la cual pasa la historia oral en el espacio museístico dice así:

When oral history was incorporated into exhibitions, the spoken word was usually transformed into text on walls, and consequently lost the multi-layered complexities and entrancing vigor of oral narration. [...] None of this does justice to oral history, nor the importance of memory as a living, active engagement between past and present. Memories should not be regarded like shards of pots, inert fragments from a long-dead past. (p. 449)

El resultado de dicha transformación es el mismo tipo de memoria muerta que se almacena en el archivo, donde el pasado se conserva inerte en las letras ahogadas en un mar de papel. En la visión del museo meriniano en El caldero de oro la materia 
ordenada de la cual se sirve el progreso aparece como el mayor enemigo de la viva memoria oral:

Congelados recuerdos de tantos siglos en la sucesión de las vitrinas, de los cicloramas, de los carteles que se extienden por los pasillos y las salas sucesivas hasta desembocar en la espectacular maqueta. [...]

Ahora duermen los objetos desarraigados en las salas solitarias, en una imaginería de sombras detenidas con cuya exaltación no se celebra realmente su historia viva, sino el momento de su muerte. [...] Ahí en una paradoja que parece burlona, se reproduce ordenadamente, muerto ya del todo y en el mausoleo, lo que fue agonizando en tantos años de ruina y abandono. (Merino, 1981: 28)

Cabe subrayar que esta imagen del museo parece corroborar la crítica realizada por Adorno, que destaca una fuerte analogía no solamente fonética con el mausoleo, el museo como nuestro memento mori. A semejanza con el descubrimiento de la historia en su sentido empático ligado a la experiencia cotidiana del individuo, realizado entre otros por Vico ${ }^{1}$ también el museo en nuestra época puede percibirse como un efecto directo de la modernización, del paso acelerado de nuestra temporalidad promovido por el rápido desarrollo de las altas tecnologías.

Según Huyssen, el principio u origen del museo en la actualidad no surge de un sentido seguro de la tradición sino más bien de su pérdida combinada con el deseo de su reconstrucción. Éstas, según opinamos, son también las causas de establecer el museo en el pueblo del narrador, donde junto a la construcción de una planta nuclear "Ha debido convertirse todo el río en una máquina para que se conmemore su pasada condición de ser vivo, el tiempo ganadero y rural de su historia milenaria" (Merino, 1981: 28). De esta manera la imagen del museo en la novela recrea y a la vez cuestiona uno de los enfoques teóricos en el museo, la teoría de la cultura hermenéuticamente orientada como compensación, acuñada en los años 80 por los filósofos alemanes neoconservadores, como Gadamer, Lubbe y Maquard. Este modelo concibe el museo como forma de compensación cultural ante una pérdida de la estabilidad:

\footnotetext{
${ }^{1}$ Giambattista Vico (1670-1744) en su obra maestra Scienza nuova reivindicó la función de fuentes poéticas y no filosóficas en el proceso de conocimiento humano, socavando de esta manera el "cogito" cartesiano como su base. Según Vico, la sabiduría poética -- la primera sabiduría de la humanidad - no partiría de una metafísica racional y abstracta sino de una metafísica sentida e imaginada de los primeros humanos. Su teoría de la memoria, entendida como un acto de interpretación que nos permite establecer conexiones entre las imágenes familiares del presente y las desconocidas del pasado, anticipa la ciencia moderna de la hermenéutica.
} 
The ever increasing speed of scientific, technical, and cultural innovation produces ever larger quantities of the non-synchronous, and it objectively shrinks the chronological expansion of what can be considered as present. [...] There's both too much and too little present at the same time [. . .] The museum compensates for this loss of stability. It offers traditional forms of cultural identity to a destabilized modern subject, pretending that these cultural traditions have not been affected themselves by modernization (Huyssen, 1995: 26)

Sin embargo, el protagonista de la novela no se beneficia de la compensación por parte del museo, ya que éste no le proporciona formas de la identidad cultural. El individuo nunca se adentra en el ámbito museístico sino que lo recrea en su memoria desde lejos y cuestiona este propósito, como si estuviera sirviéndose ahora de la teoría apocalíptica y postestructuralista del museo visto como una simulación o, en palabras de Baudrillard, "terminal cancer of our fin de siecle" (Huyssen, 1995: 25), articulada por los teóricos franceses J. Baudrillard y P. H. Jeudy y, que según nos parece, viene también compartida por Merino. Esta teoría, que puede entenderse como una prolongación posmoderna del ataque emprendido por Nietzsche contra la historia del archivo, percibe la musealización como un esfuerzo patológico por parte de la cultura contemporánea encaminado a controlar y dominar lo real para esconder el hecho de que lo real está en una agonía debido a la expansión del simulacro.

Baudrillard compara el museo con la televisión, ya que ambos son para él mecanismos de simulación y su meta no consiste en preservar sino en simular. El museo, según este modelo teórico, significa "killing, freezing, sterilizing, dehistoricizing and decontextualizing" (Huyssen, 1995: 30). Hemos podido ver que en la representación del museo en El caldero de oro éstas eran justamente las imágenes que empleaba el individuo al recordar el museo, imágenes congeladas, inertes, estériles, monótonas, decontextualizadas y sin vida, que además daban la impresión de una simulación de lo real, del pasado grandioso de esta tierra que sin embargo se disimula y en consecuencia se pierde, desembocado finalmente en el artificio de una maqueta:

\footnotetext{
El museo culmina en esta maqueta y en el gran mural que reproduce un mapa del noroeste, con las venas azules de los ríos y los brillos dorados de las Plantas. Esa maqueta y ese mapa son la apoteosis de todo lo que antecede: las armas oxidadas y prehistóricas, las viejas aras votivas del tiempo inicial, las representaciones de castros y pallozas, las piedras cistercienses... (Merino, 1981:28)
} 
La negativa visión del interior del Museo del Río se complementa con el cuestionamiento de su ubicación que en gran medida contrasta y se impone en el paisaje del río entendido como una metáfora del tiempo cronológico opuesto a la artificiosa simultaneidad temporal representada en el museo. La novedad que invade el paisaje natural destruyendo todos los viejos y auténticos vestigios del pasado, acompaña al proceso de la localización del museo:

Y se arreglaron los viejos muros, lo retejaron con cuidado, convirtieron en jardín todos los espacios antes abandonados y sucios, colocaron las naves y galerías, antes frías y oscuras, los viejos objetos domésticos, las antiquísimas reliquias, entre luces suaves, una música que, sin saber de dónde salía, lo llenaba todo de apacible quietud, y unos sillones blandos donde quedarse dormitando a la hora de la siesta. (p. 27)

Así pues, el lector de la novela se queda con la imagen de una institución de carácter comercial cuya meta consiste en venderle al consumidor el pasado en forma de un producto bien empacado "todos los días laborables y feriados" (p. 27) y cuidar de una buena publicidad, creando a la vez condiciones que complazcan al cliente.

Un museo imposible

Otra representación del museo ofrece Merino en el cuento "El museo" de la colección Cuentos del reino secreto (1982), que narra la progresiva atracción que el personaje siente por el espacio museístico hasta casi devenir su parte. La relación íntima y oscura del inconsciente que se desarrolla entre un arqueólogo y el museo genera la peripecia y mueve la trama del cuento. El anónimo protagonista y narrador del relato justifica así su afición a los viejos objetos materiales:

Mi inclinación me llevó a la arqueología. En las viejas piedras que soportaron el dintel de alguna morada para siempre desvanecida, en los cascotes de esas vasijas que unas manos ya sin remedio muertas sostuvieron, en los adornos que brillaron una vez sobre los cuerpos disipados ahora en polvo, encontraba un misterio poético vigente que me era especialmente satisfactorio, pues conformaba de algún modo mi efímero paso de hombre con un pasado y con un futuro que, profundísimos, eternos, no tenían origen ni posibilidad de consunción alguna. (Merino, 1982: 191) 
Este arqueólogo apasionado, de inclinaciones cosmopolitas, que invierte todo su tiempo y energía en múltiples dedicaciones académicas y expediciones científicas, vuelve un día al hogar familiar donde le cuentan la historia del tío Tomás, un viudo bastante mayor que convirtió la vieja casona heredada de su mujer en un museo, "museo sin fondos ni contempladores [...] museo imposible, propio de la alucinación de un viejo maniático" (Merino, 1982: 192). A pesar de todos esos motes poco halagadores que circulan por la familia, el protagonista, movido por la curiosidad y fascinado por lo pintoresco que para él tiene esta idea, decide hacerle al tío una visita de cortesía. La casona se sitúa en un espacio geográfico concreto del Vallegordo en la Omañona, una región montañosa y aislada de la provincia de León ${ }^{2}$. Allí las cosas toman un rumbo inesperado que parece escapársele del control al narrador. El tío, presintiendo su muerte cercana, le convence de que en sus ratos libres se ocupe del museo y el arqueólogo -atraído por un encanto inexplicable de aquel conjunto disperso de objetos- acepta la oferta proponiéndose ordenar y catalogar este museo incongruente.

Cuando más tarde el narrador hereda el museo en los amargos años de la posguerra, le agrada la idea de encontrar un escondite seguro y sumergirse en la casona "como en un amnios recuperado" (p. 197), donde podría olvidarse de la tristeza general que marcaba el ritmo de los calendarios de aquella época. El personaje decide quedarse en la casona un par de meses para "poner un poco de orden en aquel batiburrillo" (p. 197), actividad en la cual encuentra un descanso deleitoso. Gradualmente el cuidado del museo lo absorbe por completo apoderándose de él como una fuerza misteriosa. Solamente de vez en cuando el personaje se da cuenta del transcurso del tiempo fuera de la casona: "Un día resultó que habían transcurrido más de cuatro años" (p. 199). Cuando por fin el museo adquiere un aspecto científico y el personaje decide partir, cae en la cuenta de que ya no es capaz de hacer frente a esta fuerza extraña que domina por completo su voluntad:

\footnotetext{
${ }^{2}$ Los veintiún cuentos recogidos en Cuentos del reino secreto tienen como sustrato común la ubicación en el escenario geográfico de la provincia de León. Abunda en ellos una recreación viva y detallada del paisaje local provista de nombres de pueblos y lugares fácilmente localizables en el noroeste español. La geografía leonesa se convierte aquí en raíz de la cual brotan los hallazgos más sorprendentes, los espacios insólitos, misteriosos e inquietantes. Como resultado de ello surgen relatos arraigados en la experiencia inmediata, en la geografía vital de Merino, que demuestran que desde este espacio geográfico, que repetidas veces se torna el protagonista del cuento, los personajes pueden fácilmente acceder a lo misterioso y mágico, el envés de lo real.
} 
Percibí entonces dentro de mí una inesperada crispación. Contemplando el sendero que separaba valle abajo, sentía mi mirada y mi presencia reclamadas desde el museo como una enorme voluntad que no estuviese dispuesta a dejarme partir. [...] Aquélla fue la primera ocasión en que me sentí misteriosamente atado al museo [...] (p. 201)

Todos sus esfuerzos por alejarse del museo y del valle fallan, hasta que un día la situación se repite y el narrador le hace la oferta al sobrino que se presenta visitando el museo. Éste acepta y el arqueólogo se apresura a salir de la casona como un preso que por fin ha logrado fugarse "después de cuarenta años, seis meses y diecisiete días" (p. 204).

Como en otros relatos de Merino el espacio físico cobra aquí el protagonismo, gradualmente sustituyendo al personaje y apoderándose de su evocación para finalmente convertirse en su antagonista. En "El museo", el inicial espacio físico de la casona poblado por un sinfín de objetos materiales -debido a los afanes clasificatorios del arqueólogo- adquiere características de una representación del pasado reinventado a partir del discurso científico de clasificaciones y categorías. La memoria viva no tiene acceso al espacio cerrado de la casona donde se celebra el olvido. Viendo el museo del tío por primera vez el personaje queda embelesado por el encanto de los objetos antiguos caóticamente acumulados en la casona, por "esa apariencia de cosa vivida," que "le daba una peculiar característica" (p. 193). A pesar del caos, se nota en ellos "una extraña armonía [...] como si [...] lo que parecía sólo amontonamiento sucesivo de objetos variopintos, tuviese sin embargo un sentido y una utilidad" (p. 193). El pasado parece vivir en estos objetos del uso cotidiano y prestar su aliento vital al ámbito de la casona.

En cambio, al haberse finalizado las minuciosas tareas sistematizadoras del arqueólogo, los objetos artificialmente ordenados carecen de vida: "Madrugué mucho y recorrí de nuevo las largas salas solitarias, donde se alineaban los objetos como habitantes inertes de un mundo que no por carecer de movimiento estaba muerto" (pp. 200-201). Así pues, el arqueólogo reconstruye en este cuento el pasado estático a base de objetos materiales que cumplen la función de imágenes, no admitiendo en esta reconstrucción el proceso de la interpretación del pasado, elemento en que se sostiene la memoria viva oralmente transmitida. De hecho, los intentos del narrador del relato 
pueden interpretarse a la luz de la teoría de la arqueología de la memoria, acuñada por Foucault (1972), que concede la prioridad a la memoria disfrazada de la representación. Puesto que la tradición, según el crítico, se puede moldear, inclusive fabricar de acuerdo con los particulares requisitos del momento histórico, se propone una reconstrucción del pasado basada en las formas conmemorativas de la representación:

Images of representation as they are enshrined in the archaeological leavings of ages past provide points of stasis [...] These static representations lend history a stability that tradition can never achieve, for they are only portraying what was created in the past, not what historical actors believed they were creating. Intentions, and with them the values that traditions bear, are factored out of the historian's consideration. (Foucault, 1972: 162)

También el arqueólogo de Foucault, a semejanza del de Merino, se niega a entrar en el mundo imaginario del pasado e ignora su función en la tradición: "For as a method it professes an impossible detachment, one that denies the inspiration that living memory evokes" (p. 163). El arqueólogo, privado de la memoria viva en su método de reconstruir el pasado, cae aquí en su propia trampa; poco a poco se convierte en uno de los objetos encerrados en el museo: "Yo les sentía casi palpitar en su precisa forma física” (Merino, 1982: 201). Mientras que el arqueólogo de la representación conmemorativa hace un escrupuloso inventario de imágenes del pasado sin formar ningún juicio valorativo sobre ellas, la memoria viva que sin embargo no entra en este espacio, podría ofrecer evaluaciones de su sentido. Como indica A. Radley (1990), "Restricting the role of objects in memory to the evocation of images is a shortcoming which derives from thinking of memory only as the reflections of the solitary individual" (p. 57), excluyendo de esta manera el concepto de la viva memoria colectiva como una interacción social dentro de la tradición, es decir, la idea de que "la memoria es la facultad de retener y recordar lo pasado, siendo su elemento de expresión la tradición, que hace que todo lo recordado se convierta en un proceso social" (Pérez, 1996: 19). Este museo imposible creado con tanto esmero por el arqueólogo en su afán clasificatorio a partir de un caos de la casona que aparentaba el misterioso gabinete de curiosidades, separa y aísla los objetos de su fuente, de su contexto natural. Llega a ser la necrópolis del espacio y los objetos, el verdadero cementerio de historias que ellos poseen. Se trata de una representación aséptica y un comentario elegíaco. 


\section{Espejos rotos}

En la escena inicial de la novela La orilla oscura (Premio Nacional de la Crítica 1985) -que podría leerse como una continuación de las extrañas vicisitudes del protagonista del relato anterior, físicamente libre pero todavía perseguido por el museo- el personaje despierta un día en la habitación hotelera de una metrópoli centroamericana con una fuerte sospecha de que "aquel lugar inmenso era realmente un misterioso almacén, un extraño museo donde se custodiaban seres y objetos de diversa procedencia. Y pensó que quizá él mismo formaba parte de aquellas mercaderías, que su habitación no era sino el envase que le conservaba" (Merino, 1985: 16). El planteamiento de la realidad y de la condición del ser en ella como enigma, es decir, la duda ontológica y epistemológica incitadas en el personaje por sus frecuentes y casi obsesivas visitas al museo, asientan aquí el tono ambiguo de toda la novela y les acompañan tanto a sus personajes como al lector a lo largo de la obra. Esta vez, a diferencia de la representación del museo en la novela El caldero de oro, llegamos a presenciar una interacción que se da entre el ámbito museístico y la memoria del individuo visitante. Cabe decir que la representación del museo en La orilla oscura participa en uno de los temas centrales de Merino y el asunto nuclear de la novela, en la reflexión sobre la identidad del individuo. El mismo autor ha destacado su relevancia de la manera siguiente:

Creo que la identidad es el gran tema de nuestro tiempo. La vertiginosa sucesión de noticias, ese conocimiento, bien que superficial, pero angustioso, de los sucesos cambiantes, la conciencia de lo relativo de todo, han hecho mucho más frágil nuestro apoyo en un centro, por pequeño que pudiera ser. Parece que no somos centro de nada, y que eso es irremediable. De ahí los intentos tantas veces irracionales de determinadas recuperaciones de identidad. (Díez, 1986: 28)

Antes de adentrarnos en el análisis del museo cabe presentar un breve resumen del complejo argumento de la novela, compuesto básicamente de tres relatos principales recreados desde la memoria de sus narradores. En el primero, su protagonista de origen leonés - un profesor universitario de literatura cuyo campo de investigación es irónicamente el realismo- después de residir dando clases en los Estados Unidos, enseña de visitante en una ciudad de Centroamérica. Allí le fascina el 
museo municipal, al cual acude repetidas veces para finalmente descubrir un retrato en el cual nota el intenso parecido entre el retratado y su propio padre. Así se entera de un desconocido antepasado suyo y conoce a su descendiente, un empresario costarricense, cuya identidad asume a partir del tercer capítulo. Al final de la novela, el profesor vuelve a su antigua identidad $\mathrm{y}$, acabado el curso, regresa a su ciudad natal en el noroeste español con el fin de pasar allí las vacaciones.

Los dos primeros capítulos de la novela, que transcurren en la ciudad centroamericana, se enfocan en la peripecia de este protagonista, su desorientación entre sueño y vigilia que se debe en gran parte a las frecuentes visitas al museo. El segundo relato componente de la novela es la historia oral contada al protagonista por el piloto de la lancha durante un viaje por el río al interior del país centroamericano. Este relato incluye otros: la historia del escritor apócrifo Pedro Palaz que se vuelve un día de carne y hueso, una historia en que lo empírico se confunde con lo ficticio y finalmente un tercer relato, la leyenda jacobea de los dos amantes sacrílegos condenados a vagar eternamente. Al final del viaje -cuando el protagonista regresa al hotel- se reanuda el sueño del dios lagarto; la historia recordada ya antes de la relación de un niño con el dios lagarto. Así pues, el argumento de la novela es bastante complejo en su estructura contrapuntística de tres narraciones fundidas en una. Siguiendo la opinión del autor, podríamos decir que es una novela - filandón ${ }^{3}$. El propio Merino explica así la compleja estructura de su obra:

La estructura de las historias de filandón -un entretejerse de relatos que van sucediéndose al hilo de la historia general- me sirvió de referencia y apoyatura técnica para la novela que he publicado este año, titulada La orilla oscura. [...] Pues, conforme iba perfilando los esquemas de las diferentes historias, sentía que entre ellas -entre sus escenarios, sus protagonistas y sus tramas- por debajo de las apariencias surgían sutiles relaciones que las unificaban, hasta convertirlas en una historia única. (Merino, 1986: 37)

\footnotetext{
${ }^{3}$ El filandón, cuyo nombre etimológicamente viene de "hilar", es una costumbre campesina ya extinguida que consistía en la reunión de vecinos con el propósito de contar historias y que aparece descrita por Menéndez Pidal, su testigo presencial, del modo siguiente: "En toda esta región norteña, cuando las faenas del campo y de la matanza se han acabado, desde noviembre hasta marzo, se reúnen los vecinos en una o varias casas del pueblo, las mujeres para hilar, los hombres para algún trabajo de cestería, de madreñas o de ruedas de carro. En la amplia cocina los viejos se sientan junto al fuego [...]. Cuando la conversación decae, se lee la vida de un santo o una novela, pero preferentemente se abre paso a la tradición, con cuentos o con "cantos" (Romancero hispánico v.2, 369-70).
} 
Volviendo ahora a la relación entre el museo y el protagonista de La orilla oscura, ya desde su primera página se nota la gran influencia que este lugar tiene en la percepción del entorno por el personaje, extendiendo su condición de simulacro coherente a la realidad que rodea al personaje desorientado e incapaz de determinar su propia condición ontológica y los límites entre la vigilia y el sueño. Esta vez en su aspecto físico el museo es una fortaleza en forma de castillo que parece obstaculizar la entrada como si defendiese su contenido contra el mundo exterior con su orden temporal cronológico. A la entrada siempre hay un guardián para controlar el acceso restringido a ciertas horas del día. No obstante, a los ojos del personaje -que sospecha la simulación en todo lo que lo rodea- el edificio no tiene un aire auténticamente antiguo, le parece un "anacronismo pintoresco" (Merino, 1985: 32), como si hubiese sido levantado en la época mucho más reciente que los tiempos de la conquista. Antes de entrar, el protagonista escucha la historia oral de la instalación del museo relatada por el guardián "deteniéndose en nimias anécdotas" (p. 34) que en gran medida contrastan con las secas explicaciones escritas que acompañan a los fondos del museo.

Toda la historia oficial del país representada en el museo viene ordenada en tres partes correspondientes a los tiempos precolombinos, la colonia y la independencia.

El protagonista decide bajar primero al sótano para ver la zona más extensa dedicada al arte religioso de la colonia. Aunque al principio el ámbito museístico no difiere mucho de la visión negativa retratada en El caldero de oro, es decir, de un almacén muerto científicamente ordenado a donde la memoria viva de origen oral colectivo no tiene acceso, sin embargo, mientras el individuo se adentra en este “inmenso almacén” (p. 17), gradualmente se inicia un dinámico proceso interactivo entre el entorno físico y la conciencia del visitante que hace avivar el espacio. Las imágenes sagradas le dan la sensación de llevar una misteriosa vida escondida debajo de su aparente condición inerte: "se alineaban, se agrupaban, se enfrentaban o se daban la espalda" (p. 36). En la interacción que se libra entre los dos es el proceso interpretativo -engendrado por la imaginación nutrida también de la memoria colectivaque llega a salir al primer plano. Al visitante le invade la sensación del acecho cuando entra en la sala llena de figuras religiosas en ademanes mortificados. Las imágenes religiosas despiertan la memoria personal del individuo que llega a recrear las figuras sagradas de las iglesias familiares de su infancia: "Su sorpresa se hizo abrumadora: 
imágenes entrevistas en las iglesias familiares, o sobre algún altarcillo casero, o en el misal materno, [...] estaban todas aquí, rodeándole con la firme seguridad de una existencia real" (p. 37). Es un recuerdo confuso, ya que el personaje sabe que no son las mismas. Sin embargo, la memoria lo transporta a la infancia "como si estuviese otra vez allí” (p. 39). A continuación, su recuerdo recrea las creencias de la tradición religiosa popular oralmente transmitida sobre los patronatos de los santos: "y él se encontraba reconociendo todas aquellas advocaciones que su abuela tan bien conocía: el santo de las parturientas, de los músicos, de los zapateros, de los mudos” (p. 38).

La memoria viva del personaje al recrear las figuras sagradas las enaltece, las envuelve en un cierto aura mítico, inclusive maravilloso, que les había dado la memoria colectiva del pueblo. Sin embargo, los santos amontonados en las salas del museo sacados de su contexto original ya han perdido este aire: "toda la vieja iconografia estaba depositada a su alrededor, desalojada de sus cobijos habituales, amontonada sin la disposición y rango que les había ordenado y enaltecido en las repisas, en los altares, en las páginas o en las estampas de su recuerdo" (p. 39). La memoria-almacén carece de la habilidad de proporcionar a los objetos museísticos el aura mítica y en ello difiere de la memoria viva recreada en gran parte a partir de la oralidad popular. A veces la misma separación del objeto de su contexto funcional le proporciona una nueva aura, un tanto insólita, en la mirada del espectador, para el cual los objetos depositados en el espacio adquieren una ambigüedad y expanden sus campos semánticos, sugiriéndole nuevos significados y funciones: "Sacados de su entorno habitual, los santos objetos adquirían un aspecto ambiguo, más allá de lo litúrgico, también quirúrgico y gastronómico" y los tejidos de los gruesos brocados le recuerdan "el esplendor de nocturnos y parsimoniosos carnavales" (p. 40), hecho que hace que todo el espacio museístico parezca metamorfosearse constantemente, causándole al personaje una sensación del movimiento rápido y caótico. En consecuencia, surge la metáfora del museo como laberinto, del caos debajo de un orden aparente o, como lo percibe el personaje, de "un simulacro coherente" (p. 36).

Según K. Pomian, citado en el estudio de J. Candau (1996), la condición de objetos en un museo etnográfico es ambigua ya que cada uno de ellos pasa por una transformación marcada por las siguientes etapas: 
Il est d'abord "chose" lorsqu'il a une valeur d'usage dans l'appareil de production; il devient ensuite "déchet" lorsqu'il n'a plus cette fonction, parce qu'il est usé, détérioré ou obsolete; il peut se transformer en "sémiophore," c'est-à-dire en objet "porteur de caractères visibles susceptibles de recevoir des significations" lorsqu'il sera exposé dans un musée. Un objet "chose" devenu "sémiophore" ne peut plus être perçu comme il l'était dans sa forme originelle. (p. 98)

A este desplazamiento de funciones y contextos por el cual pasan los objetos al llegar al museo acompaña una selección ordenada del pasado digno de representarse que "is not only sustained by the world of objects and artefacts, but is, in part, shaped through the ways in which the world of things is ordered [...] What has been called a process of 'singularization' of objects" (Radley, 1990: 52-3). De esta manera, las actuales relaciones sociales y políticas dentro de la sociedad con sus ideologías dominantes influyen en esta selección e inclusive fabricación del pasado que debe conservarse: "Everyday life involves the fabrication of the past through a construction of the material world, either in its transformation or in its re-ordering" (p. 53). La estricta división de los fondos museísticos de la novela en tres zonas también puede interpretarse a la luz de estas opiniones.

A veces los objetos materiales "survive in ways unintended by makers and owners to become evidence on which other interpretations of the past can be reconstructed. This property of things - shared to some degree with written texts - has given some artefacts a special place as symbols of the past” (p. 58). Como pasa en La orilla oscura, la memoria del individuo visitante interpreta la representación material fijada en el espacio físico del museo a modo de la lectura de un texto atribuyéndoles a las imágenes un valor simbólico que permite una reconstrucción del pasado en que el recuerdo personal se alimenta de la memoria colectiva de la casa paterna o de la comunidad del pueblo nativo: "Los restos de un tiempo vivo, [...] se sentía naturalmente vinculado a ellos" (Merino, 1985: 49). Así pues, el protagonista de la novela no percibe el museo en términos de un espacio cognitivo determinado por su valor didáctico, sino más como un espacio de exploración y de reconocimiento de lo familiar, "as source of sensual stimuli, and, above all as a place where the didactic dimension, [...] is subordinated to the creation of a 'tour of sensibility' (Zunzunegui, 1994: 51). No obstante, este procedimiento -protagonizado en gran medida por la recreación 
mnemónica- contribuye en la novela a una mayor desorientación del individuo quien se cree un despierto dormido:

Y le pareció que sin conocerlos, los había visto y usado todos. Una sensación sutil, más propia del sueño, le hizo sentirse de pronto simultáneo y espectral visitante de infinitos museos, recorriendo sala tras sala que eran al tiempo pasillos domésticos y espacios entre extrañas espesuras vegetales, [...] siendo todas ajenas, pertenecían plenamente a su intimidad. [...] Volvió a sospechar que seguía inmerso en un sueño profundo, que escondía su incongruencia bajo una sutil apariencia de orden. (Merino, 1985: 50)

Todos aquellos objetos le pertenecían, y aunque también estaba seguro de no haberlos visto nunca anteriormente, una simple mirada le bastaba para reconocerlos y rememorar instantáneamente todas sus vicisitudes, su historia, como si fuesen objetos domésticos de aquel hogar primero, [...] con una confusa intuición de sueño y soledad, en aquel reconocimiento de toda la amalgama de objetos como algo evidentemente personal, ceñido a su memoria con el implacable apego de las cosas que se han vivido. Así, se encontró pensando que aquella gran sala era realmente el rincón paterno. (pp. $53-4)$

Su asombro culmina cuando durante su tercera visita al museo el protagonista encuentra un retrato que ofrece un rostro de similitud absoluta con el rostro paterno. Se entera de que el retratado es un célebre fundador de la nación y aunque su apellido no corresponde a ninguno de los suyos, recuerda:

Haber oído, en los filandones del pueblo originario, la historia de un lejano ascendiente que, abandonando las labores campesinas, había emigrado al otro lado del mar. Según alguna narración imprecisa, aquel hombre habría jugado un papel relevante en las luchas independentistas. Junto a la humildad del escaño, en los anocheceres del invierno, las vagas referencias al ilustre pariente adquirían el eco inevitable de los cuentos maravillosos (p. 65)

Luego, un profesor local de historia le cuenta un relato oral -que podría clasificarse entre el mito nacional y la leyenda- de la vida de este antepasado lejano y de su linaje. En la narración en que se nota una gran voluntad mitificadora, "capaz de enaltecer hasta las vitrinas del museo" (p. 69), los eventos de la historia oficial se mezclan con creaciones de la oralidad popular, como el momento de la muerte del héroe: "Cuentan que una mariposa espejito, como simbolizando el beso de la patria 
agradecida, se mantuvo posada sobre sus labios hasta la puesta del sol" (p. 71), o las desgracias en la familia atribuidas por el pueblo a "una maldición que fue la causa fundamental de acontecimientos tan desoladores" (p. 71). El protagonista se convierte en esta escena en un oyente embelesado por el relato que nada tiene que ver con el discurso académico:

Él escuchaba con gusto la meticulosa exposición, tan alejada en sus modos y expresiones de las formas y términos utilizados habitualmente en el seminario. [...] Y él lo contemplaba con gusto, como si asistiese al desarrollo de un espectáculo grato. Las largas reuniones en que el grupo se enredaba en las marañas de un confuso vocabulario quedaban redimidas de pronto por esta charla. (p. 71)

De esta manera, el oyente llega a complementar la memoria colectiva familiar traída del pueblo natal en la península con la tradición oral local:

Maravillado, comparaba este lejano e imaginado fulgor prócer con la vida terruñera y labriega de su inmediato linaje, [...] Recordó que, según contaban las confusas leyendas escuchadas en su niñez, aquel antepasado, [...] había sido secretario de un sacerdote paisano que llegó con el tiempo a ocupar la sede hispalense (p. 72).

La historia oral del linaje recreada aquí por el catedrático a partir de la memoria colectiva popular sirve como la única fuente del saber familiar que el personaje no ha podido encontrar en el discurso informativo y oficial del museo.

En esta tercera visión del museo meriniano la memoria viva del visitante activada por los objetos depositados allí -vistos más bien como geoglifos del pasado y no como su mera representación provista tan sólo de la información científica- inicia un proceso interpretativo y así expande este espacio, amplifica su dimensión simbólica, lo subjetiviza y pone en movimiento. Sometido a tal tratamiento por parte de la memoria y la imaginación, el museo se convierte en el espacio del olvido creativo que ofrece múltiples discursos del pasado y que también se vuelve catalizador de una negociación del sentido que se da entre el recuerdo personal y la memoria colectiva, su base y legitimación.

Este diálogo de memorias tiene su momento culminante en la escena últimamente comentada, es decir, cuando el protagonista confronta sus recuerdos con 
el relato oral del profesor. Vale también decir que en el proceso de la recreación del pasado por el individuo rodeado de objetos museísticos surge una paradoja, es decir el museo -que en palabras de Blanchot (1976) significa "esencialmente conservación, tradición, seguridad" (p. 47) y cuyo propósito original tradicionalmente reconocido siempre ha sido la confirmación de nuestro paso por el mundo y la creación de una seguridad de la condición verdadera científicamente legitimada de la realidadparticipa en la novela en el proceso de la desorientación del personaje, problematizando tanto su propia condición como la del mundo circundante y hace que el sujeto se sienta objeto:

Apilado en un inmensurable almacén. O clasificado según desconocidas ordenaciones en algún misterioso museo. (Merino, 1985: 17)

Era como si el mundo y su vida hubiesen transcurrido definitivamente y, bajo el cuidado de un celador oficioso y autoritario, se conservase todo disecado, archivado, vacío, con un fin insospechable. Era una sensación mortecina, de fría inmovilidad. (p. 55)

En este sentido la novela retoma y desarrolla los elementos ya presentes en el relato anteriormente comentado, es decir, la misteriosa fuerza encantadora que el espacio tiene para el personaje que pasivamente se deja seducir.

Ahora bien, desde su origen el museo siempre ha sido marcado por una doble polaridad. Por un lado, sigue siendo exaltado porque determina y organiza un territorio privilegiado donde las experiencias estética e intelectual se encuentran en condiciones ejemplares. Por el otro, queremos volver a insistir en ello, el museo es condenado porque suele sacar el objeto de su contexto natural, por lo tanto altera su función originaria y las condiciones originales de su recepción. Huyssen (1995) interpreta este doble tratamiento teórico del ámbito museístico desde una perspectiva distinta -que juzgamos más en sintonía con el mundo narrativo de la novela de Merinoadscribiéndole más protagonismo al espectador:

Fundamentally dialectical, the museum serves both as burial chamber of the past - with all that entails in terms of decay, erosion, forgetting - and as site of possible resurrections, however mediated and contaminated, in the eyes of the beholder. No matter how much the museum, consciously or unconsciously, produces and affirms the symbolic order, there is always a surplus of meaning 
that exceeds set ideological boundaries, opening spaces for reflection and counterhegemonic memory. (p. 15)

Merino no se aleja de este modelo doble de la percepción del museo, de hecho lo está utilizando en sus reflexiones sobre la identidad y la memoria colectiva en La orilla oscura.

Así pues, insistimos, el Museo del Río en la primera obra comentada, El caldero de oro, corresponde a la visión negativa del museo como una tumba del pasado donde se conservan tan sólo sus representaciones muertas filtradas por el discurso científico del la historia oficial que ya no tienen nada que ver con la auténtica experiencia pasada, ni tampoco con su memoria viva oralmente transmitida. Como dice A. Candau (1992): "El Museo del Río es un monumento funerario al fenecido espacio del valle. [...] El ámbito de este museo no genera acción, [...] es la necrópolis del espacio y los objetos, el cementerio de las historias que poseen ese lugar y esos objetos" (p. 57). El Museo del Río, destinado en la novela a compensar a los pueblos desaparecidos su pérdida de identidad - por lo tanto entendido en términos de un instrumento de propaganda, participa en la imposición de una falsa y rígida identidad colectiva, como opina Maleuvre (1999): "Thus the museum takes part in the process of societal rationalization that controls beings by immobilizing their identity, or simply postulating an identitybeing already a precipitate of social immobility" (p. 11). Puesto que el protagonista de El caldero de oro no inicia ninguna interacción con el espacio del museo -se mantiene alejado observándolo solamente por fuera- su memoria viva y la de sus antepasados no entran en el diálogo con este espacio. La visión negativa del museo que corresponde a su imagen tradicional del guardián de la historia oficial niega el acceso a los vivos procesos mnemónicos. Por lo tanto, produce el desconocimiento de la verdadera experiencia pasada en su contexto natural.

Por otra parte, el tratamiento negativo del ámbito museístico se aprovecha para darle características fantásticas en el relato "El museo," en el que, como hemos analizado, se atribuye al propio museo una fuerza insólita capaz de seducir al individuo que gradualmente se vuelve su víctima, atrapado en el olvido que cobijan sus paredes como un objeto más. Por fin, la representación más extensa del museo, que ocupa los dos primeros capítulos de La orilla oscura, difiere en gran medida de las anteriores 
gracias a la participación de la memoria viva. Aunque al principio retratado en términos negativos, luego el espacio del museo parece avivarse ya que el sentido de la experiencia pasada llega aquí a negociarse en un diálogo interactivo entre la memoria individual y la colectiva que los objetos museísticos incitan en el personaje. Por lo tanto, esta visión del museo corresponde más a la destacada por Huyssen (1995) que admite la participación de la memoria contra-hegemónica y la generación de sentidos nuevos.

Como resultado de ello, el personaje es capaz de reconocer su propia experiencia de la infancia en el objeto ajeno, en el otro. Por medio de este reconocimiento en los objetos que constituyen imágenes fragmentadas del pasado, el personaje solamente llega a determinar pedazos sueltos de su identidad: "It [the turn toward the residues of ancestral cultures and local traditions] reflects an attempt by ever more fragmented subjects to live with the fragments, even to forge shifting and unfixed identities out of such fragments, rather than chasing some elusive unity or totality" (Huyssen, 1995:28). Este reconocimiento no lleva al principio sino a una mayor desorientación y desconocimiento del sujeto, además el individuo no puede determinar con toda seguridad haber visto antes estas imágenes fragmentadas o solamente haberlas soñado. La memoria colectiva de los antepasados nutre su recuerdo personal y así pone en marcha todo este proceso de anagnórisis o reconocimiento proporcionándole al personaje misteriosas conexiones con los objetos contemplados. Debido a la intervención de la memoria colectiva de la oralidad popular en el proceso de la contemplación del objeto por parte del visitante, el museo en La orilla oscura deja de ser una extensión artificial del pasado transformándose en una forma espacial en que se inicia un diálogo de negociación de sentido entre el conocimiento de la historia oficial y el vivo contexto cultural recreado por la memoria del personaje. De esta manera, se postula en La orilla oscura una metamorfosis del museo en una experiencia totalmente espacial y empática, un espectáculo dinámico y vivo en interacción con el proceso mnemónico del visitante. A través de una síntesis interpretativa de objetos museísticos con la memoria e imaginación del personaje se recrean fragmentos desconectados del pasado, espejos rotos equívocos y ambiguos, parte sueño parte vigilia que sumergen al protagonista en el mayor desconcierto. De esta manera el museo llega ser metáfora de la condición existencial del personaje. 


\section{Referencias bibliográficas}

Textos Primarios

Merino, J.M. (1981). El caldero de oro. Madrid: Alfaguara.

------- . (1982). Cuentos del reino secreto. Madrid: Alfaguara / Bolsillo.

------ . J.M. (1985). La orilla oscura. Madrid: Alfaguara.

Textos Citados

Blanchot, M. (1976). La risa de los dioses. (J. A. Doval Liz, Trad.). Madrid: Taurus.

Candau, A. (1992). La obra narrativa de José María Merino. León: Diputación Provincial de León.

Candau, J. (1996). Anthropologie de la mémoire. Paris: Presses Universitaires de France.

Díez, L. M. (1986). José María Merino: El novelista como mediador. El Urogallo, 6, 26-28.

Foulcault, M. (1985). Las palabras y las cosas. México: Siglo XXI.

Foucault, M. (1972). The Archeology of Knowledge. (A.M. Sheridan Smith, Trad.). London: Tavistock.

Green, A. (1998). The exhibition that speaks for itself: Oral history and museums. En R. Perks y A. Thomson (Eds.) The Oral History reader (pp. 448-456). London y New York: Routledge.

Huyssen, A. (1995). Twilight Memories. New York y London: Routledge.

Maleuvre, D. (1999). Museum Memories. Stanford: Stanford UP.

Merino, J. M. (1986). Novelar después de todo. Las Nuevas Letras, 5, 32-38.

Pérez Taylor, R. (1996). Entre la tradición y la modernidad: Antropología de la memoria colectiva. México: Universidad Autónoma de México.

Radley, A. (1990). Artefacts, Memory and a Sense of the Past. En D. Middleton y D. Edwards (Eds.), Collective Remembering. (pp. 46-59). London: Sage Publications.

Vico, G. (1961). The New Science. Trans. Thomas Goddard Bergin and Max Harold Fisch. New York: Anchor Books.

Zunzunegui, S. (1994). Architectures of the Gaze. En S. L. López y D. Villanueva (Eds.) Critical Practices in Post-Franco Spain (pp. 43-55). (S. L. López, Trad.) Minneapolis: University of Minnesota Press.

(Artículo recibido: 07-09-2010; revisado: 07-10-2010; aceptado: 19-10-2010) 